\title{
Perbedaan Karakteristik dan Pelanggaran Lalu Lintas oleh Pengendara Sepeda Motor pada Jalan Krueng Raya-Banda Aceh dan Jalan Banda Aceh-Meulaboh
}

\author{
Farah Fadillah ${ }^{1}$ Renni Anggraini ${ }^{2}$ Muhammad Ahlan ${ }^{3}$ \\ 1Mahasiswa, Jurusan Teknik Sipil, Universitas Syiah Kuala, Banda Aceh 23111, Indonesia \\ 2,3 Jurusan Teknik Sipil, Universitas Syiah Kuala, Banda Aceh 23111, Indonesia \\ Email: farah.f@mhs.unsyiah.ac.id
}

\begin{abstract}
Violations caused by the driver of the vehicle on the highway is a factor in the emergence of traffic accidents. This can be seen from the increasing number of accidents, especially accidents caused by motorcyclists. According to the Indonesian National Police in 2016 and 2018, the number of traffic accidents by the motorcycles are the highest than other types of vehicles. The number of cases of violations and indiscipline by motorcyclists must be reference so that safety in driving can be realized. This research aims to determine the relationship between traffic volume, speed of motorcycles, and violations of motorcyclists on the magnitude of the accident rate and to find out the significant difference in violations between two roads, namely Jalan Krueng Raya-Batas Kota Banda Aceh and Jalan Banda Aceh-Meulaboh. The research was conducted by observation method on the object of research, namely traffic volume, speed of motorcycle, and violations of motorcyclist. This research uses two surveyors on each road using instruments of a survey forms and recording tools. The data processing are using the Chi-square formula and the data analysis technique used are quantitative descriptive analysis. The presentation of data using frequency distribution to get the percentage and chi-square test statistics to obtain the value of the hypothesis. The results of the research received that Jalan Krueng Raya-Batas Kota Banda Aceh as a road with a high accident rate had low traffic volume, high speed of motorcycle, and high violations of motorcyclist while Jalan Banda Aceh-Meulaboh as a road with a low accident rate had high traffic volume, low speed of motorcycle, and low violations of motorcyclist. The chi-square test received that the value is $X_{\text {count }}>$ chi-square, so the hypothesis of $H_{a}$ is accepted that there are differences in the violation of motorcyclists on the road that has high accidents and low accidents.
\end{abstract}

Keywords : Traffic Accident, Violations of Motorcyclists, Observation, Chi-Square Test, Chi-Square Formula.

\begin{abstract}
Abstrak
Pelanggaran yang diakibatkan oleh pengemudi kendaraan di jalan raya merupakan salah satu faktor timbulnya kecelakaan lalu lintas. Hal tersebut terlihat dari meningkatnya angka kecelakaan, khususnya kecelakaan yang diakibatkan pengendara sepeda motor. Menurut Kepolisian Republik Indonesia tahun 2016 dan 2018, angka kecelakaan lalu lintas akibat sepeda motor adalah yang tertinggi dibandingkan jenis kendaraan yang lain. Banyaknya kasus pelanggaran dan ketidakdisiplinan pengendara inilah yang harus menjadi acuan agar keselamatan dalam berkendara yang aman dapat terwujud. Penelitian ini bertujuan untuk mengetahui kaitan antara volume lalu lintas, kecepatan sepeda motor dan pelanggaran lalu lintas terhadap besarnya angka kecelakaan serta untuk mengetahui perbedaan pelanggaran yang signifikan pada pengendara sepeda motor antara dua ruas jalan yaitu Jalan Krueng Raya-Batas Kota Banda Aceh dan Jalan Banda Aceh-Meulaboh. Penelitian dilakukan dengan metode observasi pada objek penelitian yaitu volume kendaraan, kecepatan sepeda motor, dan pelanggaran pengendara sepeda motor. Penelitian ini menggunakan dua surveyor pada masing-masing ruas jalan dengan menggunakan instrumen berupa formulir survei dan alat rekam. Pengolahan data dilakukan menggunakan rumus chi-square dan teknik analisis data yang digunakan adalah analisis deskriptif kuantitatif. Penyajian data menggunakan distribusi frekuensi untuk mendapatkan persentase dan uji statitik chisquare untuk mendapatkan nilai hipotesis. Hasil penelitian didapatkan bahwa Jalan Krueng Raya-Batas Kota Banda Aceh sebagai jalan dengan angka kecelakaan tinggi memiliki volume lalu lintas rendah, kecepatan sepeda motor tinggi, dan pelanggaran pengendara sepeda motor tinggi sedangkan Jalan Banda Aceh-Meulaboh sebagai jalan dengan angka kecelakaan rendah memiliki volume lalu lintas tinggi, kecepatan sepeda motor yang rendah, dan pelanggaran pengendara sepeda motor rendah. Nilai yang didapat pada pengujian chi-square untuk kedua jalan bahwa nilai $X_{\text {hitung }}>$ chi-square tabel, sehingga hipotesis $H_{a}$ yang diterima yaitu ada perbedaan pelanggaran pengendara sepeda motor pada jalan yang memiliki angka kecelakaan tinggi dan angka kecelakaan rendah.
\end{abstract}

Kata Kunci : Kecelakaan Lalu Lintas, Pelanggaran Pengendara Sepeda Motor, Observasi, Uji Chi-Square,Rumus ChiSquare.

\section{Pendahuluan}

Peningkatan jumlah penduduk yang terjadi mempengaruhi peningkatan perjalanan yang kemudian berpengaruh pada kebutuhan transportasi. Peningkatan transportasi ini tentunya berdampak pada meningkatnya permasalahan transportasi salah satunya kecelakaan. 
Kecelakaan lalu lintas ialah peristiwa yang terjadi pada suatu pergerakan lalu lintas akibat adanya kesalahan pada sistem pembentuk lalu lintas yang melibatkan manusia sebagai pengemudi, kendaraan, jalan, dan lingkungan sekitar. Kecelakaan lalu lintas merupakan masalah yang hampir terjadi di seluruh negara, yang memerlukan penanganan serius mengingat besarnya kerugian yang diakibatkan. Apabila masalah kecelakaan di jalan raya tidak diperhatikan dengan baik, dikhawatirkan akan terus menimbulkan korban dari tahun ke tahun.

Penelitian ini dilakukan pada dua ruas jalan yaitu jalan yang rawan kecelakaan yaitu jalan Krueng RayaBatas Kota Banda Aceh dan jalan yang tidak rawan kecelakaan yaitu jalan Banda Aceh-Meulaboh. Jalan Krueng Raya-Batas Kota Banda Aceh yang ditinjau berada di Kecamatan Baitussalam. Menurut Kasat Lantas Polresta Banda Aceh, jalan ini adalah salah satu lokasi yang mempunyai jumlah kecelakaan lalu lintas tertinggi setiap tahunnya, lokasi tepatnya yaitu antara Sp. Cot Paya dan Gp. Cadek Kec. Baitussalam. Pada tahun 2017, jumlah kecelakaan di jalan ini yaitu 27 kasus, tahun 2018 turun menjadi 20 kasus. Sedangkan untuk jalan dengan angka kecelakaan rendah yaitu jalan Banda AcehMeulaboh yang memiliki angka kecelakaan sepanjang tahun 2017 sebanyak 4 kecelakaan dan tahun 2018 sebanyak 9 kejadian kecelakaan.

Jalan Laksamana Malahayati merupakan nama jalan yang menjadi ruas jalan Krueng Raya-Batas Kota Banda Aceh. Jalan ini merupakan jalan arteri primer kelas II-A dengan lebar jalan $12 \mathrm{~m}$ yaitu salah satu akses jalan menuju Darussalam yang menjadi pusat pendidikan dan komplek perumahan. Jalan ini juga dilalui oleh kendaraan berat menuju Pelabuhan Peti Kemas Malahayati dan salah satu jalan lintas menuju Kabupaten Pidie. Jalan Banda Aceh-Meulaboh juga menjadi objek dari penelitian ini, karena merupakan jalan lintas menuju Kabupaten Aceh Barat dan memiliki kelas jalan dan lebar jalan yang sama seperti jalan Krueng Raya-Batas Kota Banda Aceh.

Penelitian ini bertujuan untuk mengetahui kaitan antara volume lalu lintas, kecepatan sepeda motor dan pelanggaran lalu lintas terhadap besarnya angka kecelakaan serta untuk mengetahui perbedaan pelanggaran yang signifikan pada pengendara sepeda motor antara dua ruas jalan yaitu Jalan Krueng RayaBatas Kota Banda Aceh dan Jalan Banda AcehMeulaboh. Penelitian dilakukan dengan observasi pada objek penelitian yaitu volume kendaraan, kecepatan kendaraan, dan pelanggaran pengendara sepeda motor sesuai UU No. 22 Tahun 2009. Pada Survei ini ditinjau dua kategori pelanggaran yang dapat diamati langsung selama pengamatan yaitu kategori atribut pengendara dan kendaraan berupa tidak memakai helm, tidak melengkapi kaca spion, tidak menghidupkan lampu utama serta kategori perilaku pengendara berupa melawan arus lalu lintas, tidak berkonsentrasi saat berkendara, dan membawa penumpang atau barang berlebih.
Pengambilan data dilakukan selama 3 hari yaitu hari Senin, Rabu, dan Sabtu pada pukul 07.00-08.00, 12.00-13.00, dan 17.00-18.00 oleh dua surveyor menggunakan satu kamera untuk merekam aktivitas jalan serta formulir survey untuk menghitung volume lalu lintas serta pelanggaran pengendara sepeda motor. Pengumpulan data kecepatan sepeda motor dilakukan dengan menentukan panjang jalan yaitu sebesar $70 \mathrm{~m}$ dengan mengambil sampel sepeda motor sebanyak 5 sampel per 15 menit pengamatan.

Hasil penelitian umtuk survei volume lalu lintas pada jalan Krueng Raya-Batas Kota Banda Aceh yang merupakan jalan dengan angka kecelakaan yang tinggi menghasilkan volume tertinggi pada hari Sabtu yaitu $11.834 \mathrm{smp} / \mathrm{hari}$, kemudian diikuti hari Senin sebesar $10.200 \mathrm{smp} /$ hari dan hari Rabu sebesar 9.870 smp/hari. Pada jalan Banda Aceh Meulaboh sebagai jalan dengan angka kecelakaan yang rendah volume tertinggi terdapat pada hari Rabu yaitu $12.314 \mathrm{smp} /$ hari diikuti hari Senin $11.593 \mathrm{smp} /$ hari dan terendah didapat pada hari Sabtu sebesar 11.189 smp/hari. Hasil penelitian untuk kecepatan rata-rata pengendara sepeda motor pada jalan Krueng Raya-Batas Kota Banda Aceh lebih tinggi yaitu $50,28 \mathrm{~km} / \mathrm{jam}$ pada hari Sabtu, 50,08 km/jam pada hari Senin dan 50,51 km/jam pada hari Rabu. Sedangkan kecepatan rata-rata pada jalan Banda Aceh Meulaboh lebih rendah dengan kecepatan rata-rata $42,96 \mathrm{~km} / \mathrm{jam}$ pada hari Sabtu, $47 \mathrm{~km} / \mathrm{jam}$ pada hari Senin dan 44,78 $\mathrm{km} / \mathrm{jam}$ pada hari Rabu.

Hasil yang didapat diketahui bahwa volume lalu lintas pada ruas jalan dengan angka kecelakaan yang tinggi memiliki volume yang lebih rendah dibandingkan ruas jalan dengan angka kecelakaan yang rendah. Hasil penelitian untuk kecepatan rata-rata pengendara sepeda motor menentukan bahwa pada daerah rawan kecelakaan pengendara melajukan kendaraan dengan kecepatan lebih tinggi dari daerah tidak rawan kecelakaan. Hal ini juga dapat dilihat dari hasil volume lalu lintas sebelumnya bahwa volume kendaraan yang rendah menghasilkan kecepatan yang tinggi begitu pula sebaliknya jika volume yang tinggi, kecepatan pengendara lebih rendah.

Hasil penelitian untuk pelanggaran sepeda motor menghasilkan nilai signifikansi atau nilai $X_{\text {hitung }}$ masing-masing pelanggaran pada kedua jalan lebih besar dari nilai chi-square tabel. Hasil hipotesis $\mathrm{H}_{0}$ ditolak dan $\mathrm{H}_{\mathrm{a}}$ diterima, bahwa adanya perbedaan pelanggaran pengendara sepeda motor pada jalan yang memiliki angka kecelakaan tinggi dan angka kecelakaan rendah.

\section{Tinjauan Kepustakaan}

\subsection{Jalan}

Menurut Undang-Undang No 22 Tahun 2009[1], jalan adalah seluruh bagian jalan, termasuk bangunan pelengkap dan perlengkapannya yang diperuntukkan bagi lalu lintas umum, yang berada pada permukaan tanah, di atas permukaan tanah, di bawah permukaan 
tanah dan/atau air, serta di atas permukaan air, kecuali jalan rel dan jalan kabel.

\subsection{Karakteristik Lalu Lintas}

Menurut Bukhari, dkk (1997)[2], dalam perencanaan dan operasional sistem angkutan, karakteristik lalu lintas akan mencerminkan sifat-sifat aliran kendaraan dan penumpang secara kualitatif dan kuantitatif pada sistem tersebut. Sifat-sifat ini timbul dari interaksi antar pengemudi, kendaraan, dan semua fasilitas-fasilitas pelayanan lalu lintas yang muncul dalam berbagai ukuran.

\subsubsection{Voulme Lalu Lintas}

Menurut Sukirman (1999)[3], menjelaskan volume lalui lintas menunjukkan jumlah kendaraan yang melintasi satu titik pengamatan dalam satu satuan waktu (hari, jam, menit).

\subsubsection{Kecepatan Kendaraan}

Menurut Sukirman (1999)[3], menjelaskan bahwa kecepatan adalah besaran yang menunjukkan jarak yang ditempuh kendaraan dibagi waktu tempuh.

Kecepatan dapat dinyatakan dengan rumus sebagai berikut:

$$
\mathrm{V}=\frac{s}{t}
$$

Dimana :

$\mathrm{V}=$ Kecepatan kendaraan $(\mathrm{km} / \mathrm{jam})$;

$\mathrm{s}=$ Jarak yang dilalui masing-masing kendaraan $(\mathrm{km})$;

$\mathrm{t}=$ Waktu tempuh yang diperlukan masing-masing kendaraan (jam).

\subsection{Kepadatan Lalu Lintas}

Menurut Khisty dan Lall (2005)[4], mendefinisikan kepadatan (density) atau konsentrasi sebagai jumlah kendaraan yang menempati suatu panjang tertentu dari lajur atau jalan, dirata-ratakan terhadap waktu, biasanya dinyatakan dengan kendaraan per mil (kend/mil).

\subsection{Pelanggaran Lalu Lintas}

Saimuddin(2015)[5], pelanggaran lalu lintas adalah perbuatan atau tindakan yang bertentangan dengan ketentuan-ketentuan peraturan perundang-undangan lalu lintas.

\subsection{Kecelakaan Lalu Lintas}

Menurut Undang-Undang No 22 Tahun 2009[1], kecelakaan lalu lintas adalah suatu peristiwa di jalan yang tidak diduga dan tidak disengaja melibatkan kendaraan dengan atau tanpa pengguna jalan lain yang mengakibatkan korban manusia dan/atau kerugian harta benda.

\subsection{Keselamatan Lalu Lintas}

Menurut Mulyono, dkk (2009)[6], keselamatan lalu lintas merupakan upaya dalam penanggulangan kecelakaan yang terjadi di jalan raya (road crash) yang tidak hanya disebabkan oleh faktor kondisi kendaraan maupun pengemudi, namun disebabkan pula oleh banyak faktor lain seperti, kondisi alam, desain ruas jalan (alinyemen vertikal dan horizontal), jarak pandang pengemudi, kondisi kerusakan perkerasan, kelengkapan rambu atau petunjuk jalan, dan pengaruh budaya dan pendidikan masyarakat sekitar jalan.

\subsection{Observasi}

Menurut Sugiyono (1999)[7], mendefinisikan observasi sebagai teknik pengumpulan data mempunyai ciri yang spesifik bila dibandingkan dengan teknik yang lain, yaitu wawancara dan kuesioner. Kalau wawancara dan kuesioner selalu berkomunikasi dengan orang, maka observasi tidak terbatas pada orang, tetapi juga obyekobyek alam yang lain.

\subsection{Uji Chi-Square}

Menurut Santoso (2001)[8], uji chi-square termasuk salah satu alat uji dalam statistik yang sering digunakan dalam praktek. Dalam bahasa statistik nonparametrik, uji chi-square untuk satu sampel dapat dipakai untuk menguji apakah data sebuah sampel yang diambil menunjang hipotesis yang menyatakan bahwa populasi asal sampel tersebut mengikuti suatu distribusi yang telah ditetapkan.

Rumus chi-square adalah sebagai berikut:

$X^{2}=\sum \frac{(F o-F e)^{2}}{F e}$.

Keterangan:

$\mathrm{X}^{2}=$ Nilai chi-square;

$\mathrm{F}_{\mathrm{o}}=$ frekuensi pengamatan sebagai hasil suatu percobaan atau pencacahan;

$\mathrm{F}_{\mathrm{e}}=$ frekuensi harapan atau teoritis.

\section{Metodologi Penelitian}

\subsection{Obyek Penelitian}

Penelitian ini dilaksanakan pada dua ruas jalan yaitu jalan dengan angka kecelakaan tinggi yaitu jalan Krueng Raya-Batas Kota Banda Aceh yang terletak di Kecamatan Baitussalam, Kabupaten Aceh Besar, serta jalan dengan angka kecelakaan rendah yaitu ruas jalan Banda Aceh-Meulaboh.

\subsection{Teknik Pengumpulan Data}

Penelitian ini menggunakan data sekunder dan data primer. Data sekunder adalah data yang dikumpulkan dari pihak lain untuk melengkapi data primer. Data primer adalah data asli yang dikumpulkan sendiri oleh peneliti untuk menjawab masalah penelitian secara khusus. Data primer ditentukan setelah mengentahui data sekunder yang didapat sebelumnya. Pengambilan data 
primer dilakukan pada hari Sabtu tanggal 03 Agustus 2019, Senin tanggal 05 Agustus 2019 dan Rabu tanggal 07 Agustus 2019 yang dilakukan masing-masing pada pukul 07.00-08.00 WIB, 12.00-13.00 WIB dan 17.0018.00 WIB. Data sekunder yang digunakan dalam penelitian ini adalah data kecelakaan lalu lintas selama dua tahun yaitu tahun 2017 dan 2018.

\subsubsection{Pengumpulan Data Sekunder}

Data sekunder yang digunakan dalam penelitian ini adalah data kecelakaan lalu lintas selama dua tahun yaitu tahun 2017 dan 2018. Data ini diperoleh dari Kasat Lantas Polrestabes Banda Aceh yang meliputi lokasi kecelakaan, jumlah laka, jumlah korban meninggal dunia, luka berat, luka ringan serta jumlah kerugian materil. Semua data yang diterima merupakan hasil survei peneliti ke instansi tersebut dan masih merupakan data asli yang belum sama sekali mengalami perubahan atau pengolahan sebelumnya

\subsubsection{Pengumpulan Data Primer}

Pengumpulan data primer kemudian langsung dilakukan dengan meninjau ke lokasi penelitian. Data primer yang diperlukan adalah data karakteristik lalu lintas berupa data volume lalu lintas yang dilakukan dengan melihat hasil rekaman video aktifitas berkendara yang dilakukan pada ruas jalan Krueng Raya-Batas Kota Banda Aceh yaitu pada km 1,8 tepatnya didepan warung bakso Nanggroe serta pada ruas jalan Banda AcehMeulaboh daerah Ajuen tepatnya didepan Indomaret Ajuen dan kecepatan lalu lintas yang dilakukan pada waktu yang sama saat merekam video untuk menghitung volume serta data pelanggaran lalu lintas oleh pengendara sepeda motor yang tidak memakai helm, tidak lengkap kaca spion, tidak menghidupkan lampu utama, melawan arus, tidak berkonsentrasi selama berkendara serta membawa penumpang atau barang melebihi kapasitas. Pengambilan data dilakukan dengan cara merekam aktivitas lalu lintas selama waktu yang ditentukan.

\subsection{Teknik Analisis Data}

Teknik analisis data menggunakan statistik deskriptif kuantitatif dan uji chi-square. Statistik deskriptif menyajikan hasil survei observasi pelanggaran pada pengendara sepeda motor berupa persentase dan diagram serta uji chi-square unttuk mendapatkan hasil hipotesis apakah terdapat perbedaan pengendara sepeda motor pada kedua ruas jalan.

Hipotesis yang diperoleh dalam penelitian ini berupa $\mathrm{H}_{0}$ yaitu tidak adanya perbedaan antara pelanggaran pengendara sepeda motor pada jalan dengan kecelakaan yang tinggi dan jalan dengan angka kecelakaan yang rendah serta $\mathrm{H}_{\mathrm{a}}$ yaitu adanya perbedaan antara pelanggaran pengendara sepeda motor pada jalan dengan kecelakaan yang tinggi dan jalan dengan angka kecelakaan yang rendah. Pengambilan keputusan berdasarkan perbandingan chi-square dan tabel yaitu:
Jika $\mathrm{X}_{\text {hitung }}<$ chi-square, maka $\mathrm{H}_{0}$ diterima.

Jika $\mathrm{X}_{\text {hitung }}>$ chi-square, maka $\mathrm{H}_{0}$ ditolak.

\section{Hasil dan Pembahasan}

\subsection{Hasil Penelitian}

\subsubsection{Hasil rekapitulasi volume lalu lintas}

Tabel 4.1 Rekapitulasi hasil volume lalu lintas

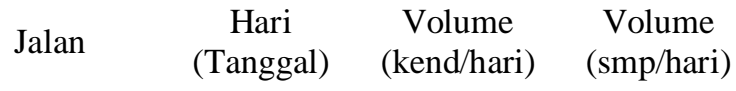

\begin{tabular}{|c|c|c|c|}
\hline \multirow{3}{*}{$\begin{array}{c}\text { Krueng } \\
\text { Raya-Banda } \\
\text { Aceh }\end{array}$} & $\begin{array}{c}\text { Sabtu (3 } \\
\text { Agt 2019) }\end{array}$ & 25580 & 11834 \\
\hline & $\begin{array}{c}\text { Senin (5 } \\
\text { Agt 2019) }\end{array}$ & 21420 & 10200 \\
\hline & $\begin{array}{c}\text { Rabu (7 } \\
\text { Agt 2019) }\end{array}$ & 20590 & 9870 \\
\hline \multirow{3}{*}{$\begin{array}{c}\text { Banda Aceh- } \\
\text { Meulaboh }\end{array}$} & $\begin{array}{c}\text { Sabtu (3 } \\
\text { Agt 2019) }\end{array}$ & 27420 & 11189 \\
\hline & $\begin{array}{c}\text { Senin }(5 \\
\text { Agt 2019) }\end{array}$ & 29360 & 11593 \\
\hline & $\begin{array}{c}\text { Rabu (7 } \\
\text { Agt 2019) }\end{array}$ & 31200 & 12314 \\
\hline
\end{tabular}

\subsubsection{Hasil rekapitulasi kecepatan pengendara sepeda} motor

Tabel 4.2 Rekapitulasi hasil kecepatan pengendara sepeda motor

Jalan $\begin{array}{cc}\text { Hari } \\ \text { (Tanggal) }\end{array} \quad \begin{gathered}\begin{array}{c}\text { Kecepatan rata- } \\ \text { rata per hari } \\ (\mathrm{km} / \mathrm{jam})\end{array}\end{gathered}$

\begin{tabular}{|c|c|c|}
\hline \multirow{3}{*}{$\begin{array}{l}\text { Krueng Raya- } \\
\text { Banda Aceh }\end{array}$} & $\begin{array}{c}\text { Sabtu (3 Agt } \\
2019)\end{array}$ & 50,28 \\
\hline & $\begin{array}{c}\text { Senin (5 Agt } \\
2019)\end{array}$ & 50,08 \\
\hline & $\begin{array}{c}\text { Rabu (7 Agt } \\
\text { 2019) }\end{array}$ & 50,51 \\
\hline \multirow{2}{*}{$\begin{array}{l}\text { Banda Aceh- } \\
\text { Meulaboh }\end{array}$} & $\begin{array}{c}\text { Sabtu (3 Agt } \\
2019)\end{array}$ & 42,96 \\
\hline & $\begin{array}{c}\text { Senin (5 Agt } \\
2019)\end{array}$ & 47 \\
\hline
\end{tabular}




\begin{tabular}{cc} 
Rabu (7 Agt & 44.78 \\
$2019)$ & \\
\hline
\end{tabular}

\subsubsection{Hasil survei pelanggaran pengendara sepeda} motor

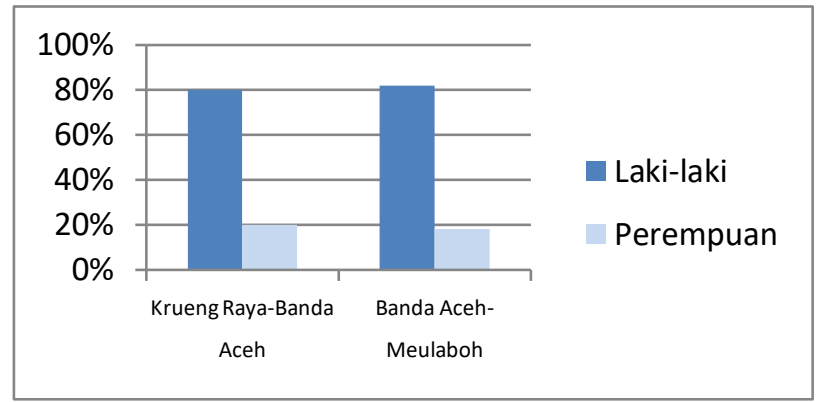

Gambar 1. Grafik pelanggaran menurut jenis kelamin

Berdasarkan gambar 1, diketahui bahwa pengendara yang melakukan pelanggaran pada jalan Krueng Raya-Batas Kota Banda Aceh adalah pengendara dengan jenis kelamin laki-laki yaitu sebanyak $80 \%$ sedangkan perempuan $20 \%$. Pada jalan Banda AcehMeulaboh pengendara yang melanggar juga didominasi laki-laki yaitu sebesar $82 \%$ dan perempuan $18 \%$.

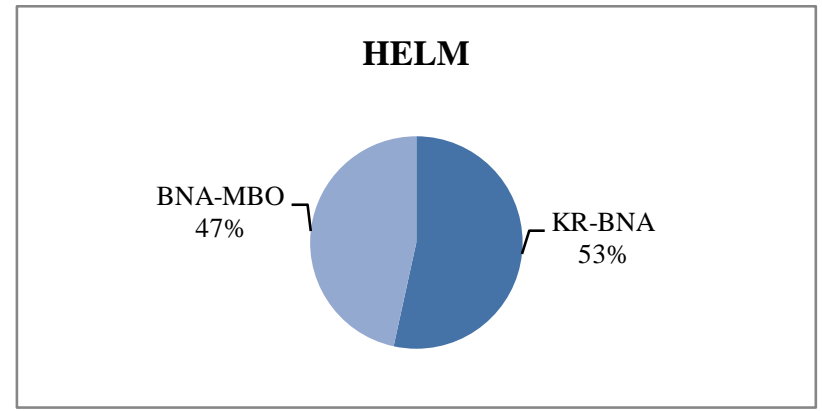

Gambar 2. Grafik pelanggaran menurut pengendara yang tidak memakai helm

Berdasarkan gambar 2 diketahui bahwa pengendara yang tidak menggunakan helm terbanyak terdapat pada jalan Krueng Raya-Banda Aceh yaitu sebesar 53\% dan pada jalan Banda Aceh-Meulaboh sebesar $47 \%$.

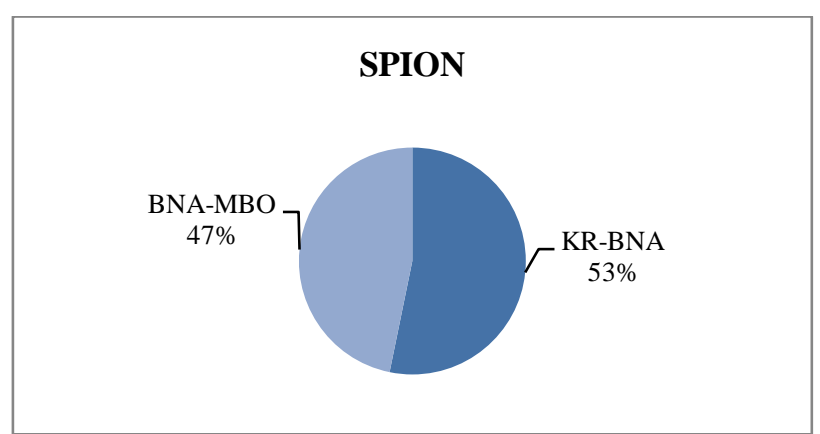

Gambar 3. Grafik pelanggaran menurut kendaraan yang tidak melengkapi kaca spion
Gambar 3 menunjukkan bahwa sebagian besar pengendara yang melanggar dengan tidak memakai spion pada kendaraannya adalah pada jalan Krueng RayaBanda Aceh sebesar 53\% sedangkan 47\% terdapat pada jalan Banda Aceh-Meulaboh.

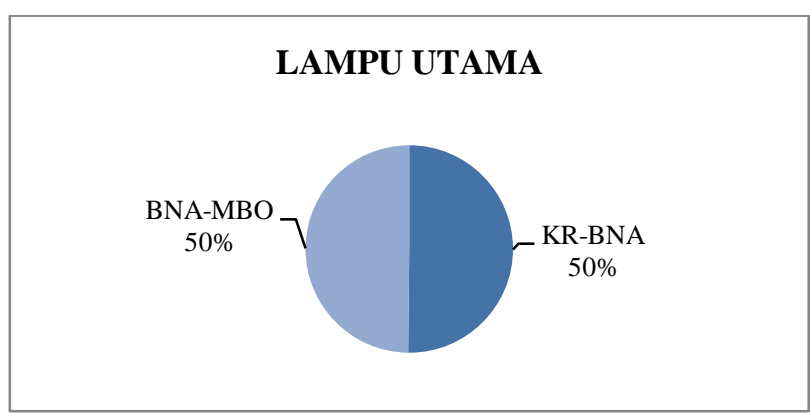

Gambar 4.Grafik pelanggaran menurut kendaraan yang tidak menghidupkan lampu utama

Pada gambar 4 menunjukkan bahwa pengendara yang tidak menghidupkan lampu utama pada kendaraannya memiliki persentase yang sama pada kedua ruas jalan yaitu masing-masing $50 \%$.

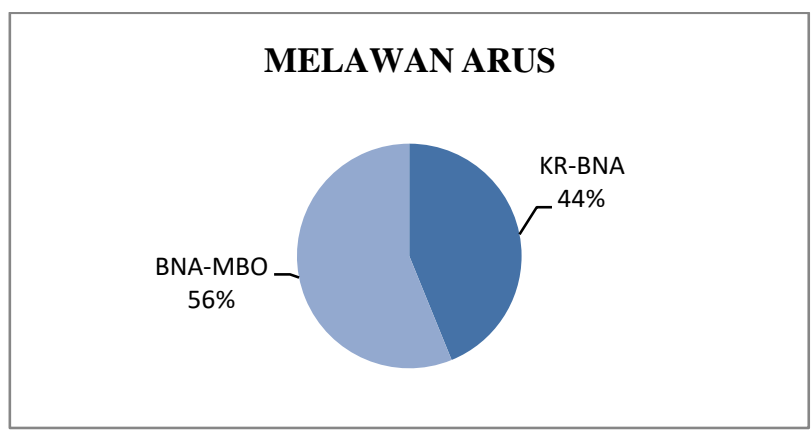

Gambar 5. Grafik pelanggaran menurut pengendara yang melawan arus

Dapat dilihat pada gambar 5 bahwa pengendara yang melawan arus terbanyak terdapat pada jalan Banda Aceh-Meulaboh yaitu sebesar $56 \%$ sedangkan $44 \%$ terdapat pada jalan Krueng Raya-Banda Aceh.

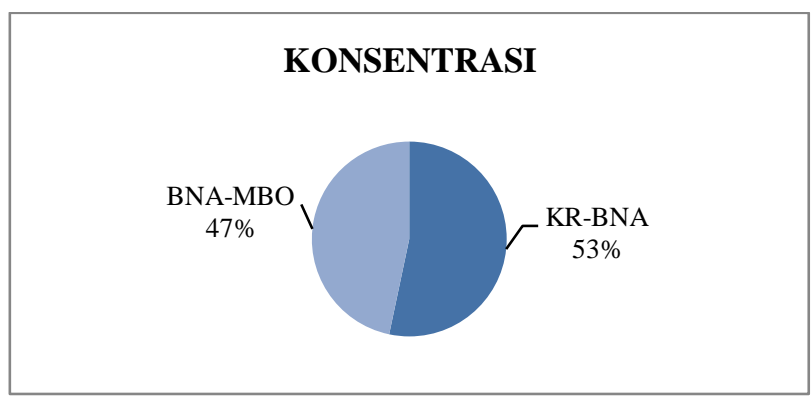

Gambar 6. Grafik pelanggaran menurut pengendara yang kurang berkonsentrasi

Berdasarkan gambar 6 menunjukkan bahwa pengendara yang tidak berkonsentrasi yaitu sebanyak 53\% pada jalan Krueng Raya-Banda Aceh dan 47\% terdapat pada jalan Banda Aceh-Meulaboh. 


\section{KAPASITAS PENUMPANG}

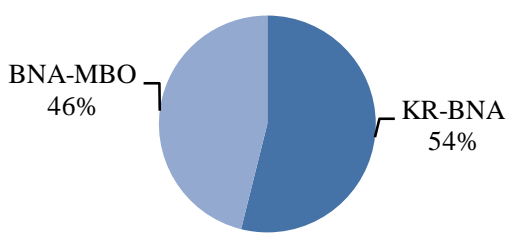

Gambar 7. Grafik pelanggaran menurut pengendara yang membawa penumpang atau barang berlebih

Pada gambar 7 menunjukkan bahwa pengendara yang membawa kapasitas melebihi kapasitas sebesar $54 \%$ pada jalan Krueng Raya-Banda Aceh sedangkan pada jalan Banda Aceh-Meulaboh sebesar $46 \%$.

Tabel 4.3 Rekapitulasi nilai chi-square

$$
\text { Nilai chi-square hitung }
$$

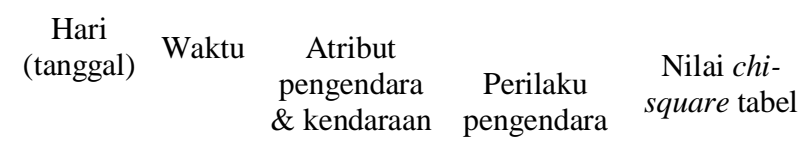

\begin{tabular}{|c|c|c|c|c|}
\hline \multirow{3}{*}{$\begin{array}{c}\text { Sabtu (3 } \\
\text { Agt } \\
\text { 2019) }\end{array}$} & $\begin{array}{c}07.00- \\
08.00\end{array}$ & 6,01 & 6,83 & \multirow{9}{*}{5,99} \\
\hline & $\begin{array}{c}12.00- \\
13.00\end{array}$ & 6,74 & 20,9 & \\
\hline & $\begin{array}{l}17.00- \\
18.00\end{array}$ & 6,78 & 6,36 & \\
\hline \multirow{3}{*}{$\begin{array}{c}\text { Senin }(5 \\
\text { Agt } \\
2019)\end{array}$} & $\begin{array}{c}07.00- \\
08.00\end{array}$ & 37,1 & 8,65 & \\
\hline & $\begin{array}{c}12.00- \\
13.00\end{array}$ & 9,75 & 6,5 & \\
\hline & $\begin{array}{l}17.00- \\
18.00\end{array}$ & 6,37 & 6,12 & \\
\hline \multirow{3}{*}{$\begin{array}{c}\text { Rabu (7 } \\
\text { Agt } \\
2019)\end{array}$} & $\begin{array}{c}07.00- \\
08.00\end{array}$ & 32,55 & 6,22 & \\
\hline & $\begin{array}{c}12.00- \\
13.00\end{array}$ & 6,45 & 7,63 & \\
\hline & $\begin{array}{c}17.00- \\
18.00\end{array}$ & 8,6 & 6,14 & \\
\hline
\end{tabular}

\subsection{Pembahasan}

Hasil penelitian umtuk survei volume lalu lintas pada jalan Krueng Raya-Batas Kota Banda Aceh yang merupakan jalan dengan angka kecelakaan yang tinggi menghasilkan volume tertinggi pada hari Sabtu yaitu $11.834 \mathrm{smp} /$ hari, kemudian diikuti hari Senin sebesar $10.200 \mathrm{smp} /$ hari dan hari Rabu sebesar $9.870 \mathrm{smp} / \mathrm{hari}$.
Pada jalan Banda Aceh Meulaboh sebagai jalan dengan angka kecelakaan yang rendah volume tertinggi terdapat pada hari Rabu yaitu $12.314 \mathrm{smp} /$ hari diikuti hari Senin $11.593 \mathrm{smp} / \mathrm{hari}$ dan terendah didapat pada hari Sabtu sebesar 11.189 smp/hari. Hasil penelitian untuk kecepatan rata-rata pengendara sepeda motor pada jalan Krueng Raya-Batas Kota Banda Aceh lebih tinggi yaitu $50,28 \mathrm{~km} / \mathrm{jam}$ pada hari Sabtu, 50,08 $\mathrm{km} / \mathrm{jam}$ pada hari Senin dan 50,51 km/jam pada hari Rabu. Sedangkan kecepatan rata-rata pada jalan Banda Aceh Meulaboh lebih rendah dengan kecepatan rata-rata $42,96 \mathrm{~km} / \mathrm{jam}$ pada hari Sabtu, $47 \mathrm{~km} / \mathrm{jam}$ pada hari Senin dan 44,78 $\mathrm{km} / \mathrm{jam}$ pada hari Rabu.

Hasil yang didapat diketahui bahwa volume lalu lintas pada ruas jalan dengan angka kecelakaan yang tinggi memiliki volume yang lebih rendah dibandingkan ruas jalan dengan angka kecelakaan yang rendah. Hasil penelitian untuk kecepatan rata-rata pengendara sepeda motor menentukan bahwa pada daerah rawan kecelakaan pengendara melajukan kendaraan dengan kecepatan lebih tinggi dari daerah tidak rawan kecelakaan. Hal ini juga dapat dilihat dari hasil volume lalu lintas sebelumnya bahwa volume kendaraan yang rendah menghasilkan kecepatan yang tinggi begitu pula sebaliknya jika volume yang tinggi, kecepatan pengendara lebih rendah.

Hasil penelitian untuk pelanggaran sepeda motor menghasilkan nilai signifikansi atau nilai $X_{\text {hitung }}$ masingmasing pelanggaran pada kedua jalan lebih besar dari nilai chi-square tabel. Hasil hipotesis $\mathrm{H}_{0}$ ditolak dan $\mathrm{H}_{\mathrm{a}}$ diterima, bahwa adanya perbedaan pelanggaran pengendara sepeda motor pada jalan yang memiliki angka kecelakaan tinggi dan angka kecelakaan rendah.

\section{Kesimpulan dan Saran}

\subsection{Kesimpulan}

Jalan Krueng Raya-Batas Kota Banda Aceh sebagai jalan dengan angka kecelakaan tinggi memiliki volume lalu lintas rendah, kecepatan sepeda motor tinggi, dan pelanggaran pengendara sepeda motor tinggi sedangkan jalan Banda Aceh-Meulaboh sebagai jalan dengan angka kecelakaan rendah memiliki volume lalu lintas lebih tinggi, kecepatan sepeda motor yang lebih rendah, dan pelanggaran pengendara sepeda motor yang rendah, sehingga ditarik kesimpulan bahwa jalan Krueng RayaBatas Kota Banda Aceh banyak terjadi kecelakaan karena pengendara sepeda motor cenderung membawa motor dengan kecepatan yang tinggi karena ruas jalan yang memiliki volume kendaraan yang rendah sehingga pengendara menjadi leluasa saat berkendara.

Pada pengujian chi-square menghasilkan nilai $\mathrm{X}_{\text {hitung }}>$ chi-square, sehingga menghasilkan hipotesis $\mathrm{H}_{0}$ ditolak dan $\mathrm{H}_{\mathrm{a}}$ diterima yaitu ada perbedaan pelanggaran pengendara sepeda motor yang signifikan pada jalan yang memiliki angka kecelakaan tinggi yaitu Jalan Krueng Raya-Batas Kota Banda Aceh dan angka kecelakaan rendah yaitu Jalan Banda Aceh-Meulaboh. Hasil tersebut membuktikan bahwa jalan yang memiliki 
angka kecelakaan lebih tinggi karena pelanggaran pengendara sepeda motornya juga lebih tinggi, begitupun sebaliknya jalan yang memilki angka kecelakaan yang rendah, pelanggarannya lebih rendah pula.

\subsection{Saran}

Pada penelitian ini diperoleh responden yang pernah mengalami kecelakaan dengan luka-luka dan kerusakan harta benda yang parah didominasi oleh pengendara sepeda motor berusia muda. Hal ini dapat menjadi pertimbangan untuk melakukan penelitian dengan mengambil sampel lebih spesifik yaitu responden dengan usia muda.

\section{Daftar Pustaka}

[1] Pemerintah Indonesia, Undang-Undang Republik Indonesia Nomor 22 Tahun 2009 tentang Lalu Lintas dan Angkutan Jalan, 2009.

[2] Bukhari, R.A, dkk, Rekayasa Lalu Lintas I, Bidang Studi Teknik Transportasi Fakultas Teknik Universitas Syiah Kuala, Banda Aceh, 2007

[3] Sukirman S., Dasar-Dasar Perencanaan Geometrik Jalan, Nova, Bandung, 1999.

[4] Khisty C. J. dan B. K. Lall, Dasar-Dasar Rekayasa Transportasi Jilid I, Erlangga, Jakarta, 2005.

[5] Saimuddin, L, Tinjauan Kriminologis Pelanggaran Lalu Lintas Secara Masif yang dilakukan oleh Pengantar Jenazah di Kota Makasssar, Fakultas Hukum, Universitas Hasanudin, Makassarm 2015.

[6] Mulyono A.T., B. Kushari dan H. E. Gunawan, Audit Keselamatan Infrastruktur Jalan (Studi Kasus Jalan Nasional KM 78-KM 79 Jalur Pantura Jawa, Kabupaten Batang), Jurnal Teknik Sipil 16(3): 163-174, 2009.

[7] Sugiyono, Metode Penelitian Kombinasi (Mixed Methods), Alfabeta, Bandung, 1999.

[8] Santoso S., SPSS Versi 10 Mengolah Data Statistik Secara Profesional, Elex Media Komputindo, Jakarta,2001. 